\title{
CINEFILIA, UM ROMANCE DE FORMAÇÃO
}

\author{
Pablo Gonçalo ${ }^{1}$
}

\begin{abstract}
Resumo: Resenha do livro Cinefilia: invenção de um olhar, história de uma cultura, 1944 - 1968, de Antoine de Baecque (tradução André Telles, Cosac Naify, 2010).
\end{abstract}

Palavras-chave: Cinefilia. Critica cinematográfica. Nouvelle vague.

Abstract: Critical review of the book by Antoine de Baecque Cinephilie. Invention d' un regard, histoire d'une culture, 1944-1968. First published in french in 2003 and translated into portuguese in 2010.

Keywords: Cinephilia. Film criticism. Nouvelle vague.

\section{Introdução}

Claro que um filme nunca é recebido e interpretado de maneira uniforme. O significado de uma imagem artística é necessariamente inesperado, uma vez que se trata do registro de como um indivíduo viu o mundo `a luz de suas próprias idiossincrasias. (TARKOVSKI, 2002: 204)

Muito comentada e citada na história do cinema, a trajetória da geração da nouvelle vague - seus antecessores, seus desdobramentos - ganha um estudo histórico minucioso com o lançamento de Cinefilia: invenção de um olhar, história de uma cultura, de Antoine de Baecque. A originalidade da obra está no seu ponto de partida: opta-se por retratar aquela geração pelo viés da paixão pelo cinema o que revela uma porta de entrada certeira para compreender a singularidade da movimentação cinematográfica (e política) que marcou a França entre os anos sessenta e setenta. Mais do que uma geração de cineastas e críticos, De Baecque nos mostra uma inquietação cultural que buscou uma maneira exemplar de lidar com a experiência cinematográfica. Pela cinefilia, e por esses ensaios franceses, chega-se a um ethos, um modo de comportamento que se alastrou pelo mundo, e infere-se certos fundamentos éticos, estéticos, que guiaram e guiam gerações de diretores, críticos e espectadores. Situada num terreno fluido, movediço, a cinefilia também apontaria para o entrelaçamento entre as formas de pensar, fazer, e, sobretudo, de lidar e interagir com o audiovisual.

\footnotetext{
${ }^{1}$ Doutorando em Comunicação pela UFRJ. Docente da Pós-Graduação em Produção Cultural da Universidade Cândido Mendes e do curso de Cinema e Mídias Digitais do IESB. E-mail: pablogoncalo@gmail.com
} 
Nesse sentido, a cinefilia seria uma categoria apropriada para compreensão de parte do fenômeno da recepção cinematográfica. Nos campos da comunicação e do cinema, essas pesquisas de recepção conquistam, pouco a pouco, um espaço mais consistente. Segundo Mascarello, essas investigações sobre a recepção cinematográfica podem ser classificadas em cinco vertentes, tais como as teorias feministas do cinema, os estudos da intertextualidade contextual, os estudos históricos de recepção, os estudos etnográficos da audiência e a política da localização (MASCARELLO, 2006:4). Trata-se, por essas perspectivas, de compreender variações e aspectos socioculturais das formas como uma obra é comunicada, recebida e discutida. Frente ao que conhecemos como espectador, portanto, haveria diversas mediações, modos distintos de fruição (e leitura cultural) dos conteúdos audiovisuais.

De maneira transversal, o cinéfilo, como um tipo de espectador, poderia estar presente em qualquer uma das linhas de pesquisa que apontamos. A paixão que emana da relação com a linguagem audiovisual teria uma magia tão ilimitada quanto de difícil apreensão. Para De Baecque, contudo, a cinefilia teria uma mediação comunitária singular: ela envolveria o espectador numa febre de participação e luta por uma mítica essência da linguagem cinematográfica. Ao compreender a cinefilia - francesa e mundial - como um fenômeno cultural, De Baecque nos sugere uma maneira bem peculiar de abordar a recepção audiovisual. Diferente do espectador genérico e amorfo tal como o contabilizado pelas bilheterias dos blockbusters, a cinefilia traduziria uma forma íntima e intensa de relação com a linguagem audiovisual. Nesse sentido, o cinéfilo equivale para o cinema ao que seria a figura do leitor imaginário (ou ideal) para a literatura (PIGLIA, 2006); ou seja, um amante, um caso quase extremo de indivíduos e sujeitos que se vêem, se formam e criam numa relação com o mundo permeada por letras (para o leitor) ou sons e imagens em movimento (para o cinéfilo).

Se o cinema é a metáfora das relações comunitárias no século XX ocidental, a cinefilia seria sua versão clandestina, seu prolongamento individual sob a forma de um ritual íntimo. A história pode apoderar-se dessa paixão? (BAECQUE, 2010: 34)

Traçada, portanto, por uma multidão de solitários (e de indivíduos comuns), a história da cinefilia tangencia a clandestinidade. Escrita, é claro, como uma história do efêmero, feita às escuras, entre câmeras, salas de projeção e cafés, com documentos esparsos, depoimentos raros e conceitos imprecisos. Uma micro-história, próxima à da vida privada, na qual revelase mais o afã de uma vivência cultural agitada do que a ativação do motor da grande história. 
Precisas e bem definidas, no entanto, as minudências da pesquisa de Baecque nos revelam como esse modo - íntimo - de viver o cinema acabou por reavivar a história da sétima arte. Se um filme é tanto o que se diz e o que se escreve sobre ele, como nos lembra Pierre Sorlin (MASCARELLO, 2006: 06), o cinéfilo também seria aquele indivíduo que se alastra pela obra de forma a reinventá-la e, no caso da nouvelle vague, a reinventar a própria linguagem cinematográfica.

$\mathrm{Na}$ França, a cinefilia moderna teria um início bem claro nos anos que seguiram a ocupação nazista e a sua resistência - a liberação. Discretamente, dois movimentos ligados ao cinema tomaram a cena: o advento de dezenas de cineclubes e a consolidação da cinemateca francesa, liderada por Henri Langlois. Em ondas crescentes e acumulativas, surgiram diversas revistas especializadas (Positif, Arts, Combat, France Observateur, Cahiers du Cinema, Trafic), associações, festivais, e uma intensificação da cinefilia por meio de escritos, discursos e reflexões sobre o cinema.

Composto sobretudo de retratos, o livro de De Baecque dispõe uma narrativa que perpassa personagens de três gerações. De forma cronológica, observa-se as trajetórias de André Bazin, Georges Sadoul, François Truffaut, Roger Tailleur, Bernard Dort e Serge Daney. Enfileirados de tal forma ele são tão somente críticos de cinema, editores de revista, cineastas e polemistas. Sob o olhar de De Baecque, contudo, eles ativam formas específicas de pensar e lidar com o cinema. Com cada um deles o cinema dança um compasso e um estilo distinto. Ora político, ora estético, polêmico e irreverente, ou mesmo apaixonado, nostálgico e melancólico - o cinema, com esses críticos, revela-se como estados de espíritos individuais, comunitários e, quiçá, universais, formas de lidar com a inquietação inerente à paixão cinematográfica que motiva a vida de cada cinéfilo.

\section{A cinefilia como um modo de vida}

É por meio das polêmicas que perpassaram o cinema americano que De Baecque nos mostra o melhor da força desse momento cultural. Numa das tônicas predominantes, havia o embate interno, na cultura francesa, em reconhecer o valor e o talento artístico de autores então considerados como menores, meros diretores de "filme b", como Howard Hawks e Alfred Hitchcock.

“(...) o papel da cinefilia terá sido o de legitimar esse cinema americano clássico, vivo, ativo, tônico, excitante, extravagante, na época considerado um espetáculo de puro entretenimento, e por isso a princípio temido pelo cinema francês do pós-guerra. (...) A cinefilia, nesse sentido, não é o culto do 
amor maldito, do artista rebelde e marginal, mas antes um projeto de transferência de discurso, uma captação de objeto: aplicar a cineastas que trabalham no cerne do sistema comercial um olhar e palavras anteriormente reservados aos artistas e intelectuais de renome". (DE BAECQUE, 2010: 40 $-41)$

Necessariamente, a história do reconhecimento do cinema americano com um status de arte passa por André Bazin. Com De Baecque, viajamos para 14 de maio de 1945, alguns instantes antes de mais uma sessão para estudantes e operários. Lá está ele: tirando do banco de trás do seu calhembeque $3 \mathrm{CV}$ cincos pesados rolos do filme Trágico Amanhecer. Timidamente, Bazin faz um prólogo do filme de Marcel Carné, chama a atenção para aspectos estéticos, exibe a película e, logo em seguida, discute com a plateia. É a tríade clássica (e quase religiosa) de todo cineclube: introdução, projeção e debate.

Entre tantas sessões comunitárias, Bazin aglutinou um grupo de jovens críticos e cinéfilos e, com eles, criou a lendária Cahiers du Cinema. Bazin legou `a geração da nouvelle vague os conceitos pilares para a construção do cinema moderno. Elegeu cineastas-guia como Orson Welles, Roberto Rosellini e Jean Renoir para comprovar uma certa direção do cinema rumo a transubstanciação do real.

Ensaísta de fôlego, avesso a qualquer dogmatismo, Bazin apontava para diretores que acreditavam na montagem e para outros que apostavam na realidade (BAZIN, 2002: 52). Entre ambas as pontas, desvela-se a perseverança no jogo e posicionamento entre câmera, atores e decupagem, que poderia ser encontrada nas principais obras e nos mais talentosos diretores. A engenhosidade da ênfase na mis-en-scene está em valorizar procedimentos estilísticos que ultrapassam dicotomias estanques como arte e entretenimento; ou filmes de "qualidade" e filmes comerciais. Afinal, a mis-en-scene manifestar-se-ia também em westerns, filmes policiais e melodramas - filmes de gênero, filmes industriais. É por esse viés que o cinema americano clássico foi recuperado e valorizado: como uma das principais referências audiovisuais de ricas experiências na mis-en-scene, a despeito de sua verve comercial.

Quase como um antagonista, num típico roteiro de filme clássico, De Baecque retrata Georges Sadoul, um crítico extremamente político, de verve stalinista, que manteve inúmeras polêmicas com Bazin e outros críticos da Cahiers. Sadoul tornou-se conhecido por ter escrito a História do Cinema Mundial, um importante compêndio com diretores e filmes de vários países. De estilo ideológico, focado nos conteúdos e nas mensagens dos filmes, Sadoul encarnou um espírito enciclopédico e socialista que também teve grande repercussão para o que veio a ser o cânone e a construção do discurso sobre a história do cinema. Não por acaso, 
as rusgas entre Sadoul, Bazin \& cia perpassavam sobretudo o cinema americano, que, para Sadoul, era despolitizado e, nenhum outro além dos dez diretores de uma lista de perseguidos pelo senador McCarthy mereceria sua atenção.

A síntese desse debate entre Bazin e Sadoul, que polarizava o formalismo estético com posições políticas, traduz-se na trajetória de François Truffaut. De cinéfilo, Truffaut transforma-se num crítico profissional com diversas incursões em terrenos ideológicos. De Bacque nos narra as várias versões, idas e vindas por mais de dois anos, do seu famoso ensaio "uma certa tendência do cinema francesa" que foi um dos alicerces da chamada política dos autores, a qual apontava o diretor como o principal artista da obra cinematográfica.

Após a intervenção crítica de Truffaut, houve uma politização da estética cinematográfica. Nos debates, a moral tornava-se uma questão de travelling e todo travelling poderia ser lido moralmente. Da teoria à práxis, Truffaut também exerceu um importante protagonismo na passagem da critica `a realização, atuando nos bastidores e redirecionando a Cahiers rumo a defesa explícita do cinema moderno.

Como num romance de formação, De Baecque narra a passagem dessa adolescente inquietação cinéfila para sua atitude política, madura. Trata-se do caso Henri Langlois, então diretor da cinemateca, principal abrigo e útero desses cinéfilos. Laconicamente, o então ministro da cultura André Maulraux demite Langlois e acaba por suscitar a ira dos "jovens turcos", como essa geração era conhecida. Godard publica cartas abertas, vorazes. Um movimento de resistência ganha o apoio de cineastas europeus, americanos e japoneses. Os jovens cinéfilos faziam piquetes e manifestações para reivindicar o direito público de ver as melhores obras da história do cinema. Forte, o movimento é considerado por diversos historiadores como o prenúncio de maio de 68. Por amor ao cinema, nascia o amor à política.

Com esses desassossegos aparentemente paradoxais e contraditórios, a nouvelle vague utilizava-se da crítica independente para inventar uma existência cultural digna ao cinema (FRODON, 2008: 44). Reconhecia-se, de um lado, o valor artístico de certos filmes tidos como de segunda categoria, evidenciando que arte e entretenimento não são necessariamente contraditórios mas constituintes, intrínsecos `a sétima arte. De outro lado, inaugurava-se uma forma de produção autônoma, independente, que exigia a liberdade da criação e expressão cinematográfica frente a qualquer modelo de produção. Esses dois pilares legaram modos subjetivos de ler os filmes e um alcance global desses preceitos. 


\section{A cinefilia como crítica cultural}

Na dinâmica de arte que vivenciamos hoje - hiper-institucionalizada, veloz, ágil em seus agenciamentos com o capital -, a flexibilidade, o deslocamento e a fluidez se tornaram um valor a ser incorporado pelo sujeito-autor, que aí se constitui como nó de uma rede que o ultrapassa". (BASBAUM, 2001: 19).

É claro que nem todo cinéfilo torna-se um crítico. No entanto, os conceitos que estão implícitos na obra de De Baecque mostram que a cinefilia pode significar uma forma de atuação singular, para além do engajamento estético e político. Uma atuação cultural frente aos atos impessoais e destituídos de história e memória que marcam a indústria cinematográfica. A crítica, tal como exercida por essas gerações, preocupa-se em descobrir o que há de cinematográfico em cada filme, em cada fotograma, em cada revolução do audiovisual.

A geração francesa retratada por De Bacque foi exímia em atuar de forma autônoma. Não sucumbiu aos ditames da imprensa e da mídia da época. Tampouco submeteu-se às grandes teorias acadêmicas, pois aconteceu anos antes da chegada dos estudos de cinema nas universidades. $\mathrm{O}$ mais interessante é que esse vácuo institucional propiciou um contato direto com as obras e com uma reflexão que se impunha num ritmo e numa velocidade próxima a dos lançamentos dos filmes comerciais da época. Uma parte considerável da história da Cahiers du Cinema, tão bem contada por De Baecque, concentra-se em narrar essa premente necessidade de revisão e reinvenção que os críticos e cinéfilos precisam passar. Como se fosse um incessante romance de formação, que atravessa não apenas gerações, mas pedaços da história do cinema. Se a etimologia da palavra crítica significa "colocar em crise" (FRODON, 2008: 09), o papel contemporâneo dessa cinefilia talvez também seja instaurar crises constantes na crítica, como instituição, e nas formas de lidar com a visão, a fruição e a percepção do fenômeno audiovisual.

Cinéfilo, ao menos isso nos tornamos. (...) Para não ser mais esse cinéfilo (há outros), teria sido necessário saber vaiar rapidamente as 'atrações', interpretar no 'teatro' com elas, rir delas, afastá-las, não dar a mínima como se faz em Fellini. Tarde demais. A vergonha de ter visto e não ter dito nada carrega com ela o desafio de tudo ver, de sustentar o olhar, estar de acordo com as aventuras mais aberrantes do cinema. Ver tudo como em um zoológico, um 'tudo' fechado, com tranca dupla, na prisão da tela. Pelo medo retrospectivo de ter tido que responder 'presente' no teatro da piedade, a criança começa a esperar tudo do cinema da crueldade. Isso durou muito tempo, e isso não terá, sem dúvida, um fim. (DANEY, 2009: 27)

De certa forma, esse gesto crítico e cinefílico precisa reinventar-se toda vez que o próprio cinema mostrar-se distinto e revolucionar-se tecnologicamente. É nesse sentido que 
devemos estranhar - ou mesmo criticar - um certo olhar melancólico de De Baecque. É certo: os cinemas do mundo todo fecham as portas, fogem das ruas, transformam-se em multiplex, viram igrejas. Houve, sim, um abalo desse olhar apaixonado após a consolidação da TV, do vídeo e do Dvd. Antes pública e na rua, a cinefilia enclausura-se entre paredes de apartamentos e expande-se em redes interconectadas em novos modos de compartilhamento, troca e sociabilidade (ROSENBAUM, 2010). Essa melancolia não nos ajuda a ver e a atuar como cinéfilo nisto que pulsa e nos é contemporâneo. Protagonista ao longo do século XX, o cinema muda de cara e se maquia de forma distinta nesse novo milênio.

É curioso constatar como o velho Godard de hoje percebe essas mudanças. Audaz, ele lançou o seu Film Socialism simultaneamente em Cannes e na internet. Pois sabe que ali, entre as telas de computador e os downloads ainda proibidos, encontram-se cinéfilos tão afoitos como foram os jovens turcos de sessenta anos atrás. Não por acaso a última frase do seu filme - em meio ao símbolo do FBI - soa profética: “quando a lei não é justa, a justiça vem antes da lei”.

\section{Referências bibliográficas}

BASBAUM, Ricardo: "Cica \& sede de critica" IN: BASBAUM, Ricardo (Org.): Arte contemporânea brasileira: textura, dicções, ficções, estratégias. Rio de Janeiro: Rios Ambiciosos, 2001.

BAZIN, André: Qu'est-ce que le cinema?. Paris, Les éditions du Cerf, 2002.

DANEY, Serge: A rampa: cahiers du cinema, 1970-1982. São Paulo: Cosac Naify, 2007.

DE BAECQUE, Antoine: Cinefilia: invenção de um olhar, história de uma cultura, 1944 1968. São Paulo: Cosac Naify, 2010.

FRODON, Jean-Michel: La critique de cinema. Paris: Cahiers du Cinema/CNDP, 2008.

MASCARELLO, Fernando: "Mapeando o inexistente: os estudos de recepção cinematográfica, porque não interessam a universidade brasileira?" Unirevista, Vol. 1, numero 03. Julho, 2006.

PIGLIA, Ricardo: O último leitor. São Paulo: Companhia das Letras, 2006.

ROSENBAUM, Jonathan: Goodbye Cinema. Hello Cinephilia. Film Culture in Transition. Chicago: The University of Chicago Press, 2010.

TARKOVSKI, Andrei: Esculpir o tempo. São Paulo: Matins Fontes, 2002. 